\title{
Improved postoperative outcomes with stentless aortic valve: a community hospital experience
}

\author{
S A Olenchock, Jr, J F Reed III, A Brown, F M Garzia
}

Heart 2003;89:551-552

S . Luke's Hospital is a 436 bed community teaching hospital in Bethlehem, Pennsylvania, USA, performing an average of 750 open heart surgeries yearly by four cardiothoracic surgeons. The type of prosthesis for aortic valve replacement (AVR) chosen is based on durability, safety of postoperative anticoagulation, ease of implantation, and postoperative haemodynamic performance.

Surgeons at St Luke's Hospital began using the Toronto SPV (St Jude Medical, St Paul, Minnesota, USA) in 1997. Within a short time it was observed that a larger size Toronto SPV valve could be inserted into a smaller aortic root than mechanical or stented bioprosthetic valve. In addition, there was a perceived notion that patients who received a Toronto SPV valve recovered better during the early postoperative period than did those who received a mechanical or stented bioprosthetic valve. This observation was consistent with previously published outcomes that showed improved early and late haemodynamics with the Toronto SPV valve. ${ }^{12}$

Consequently, a change in valve selection from mechanical to bioprosthetic valves was observed, with the increased use of bioprosthetic valves being related to the increased use of the Toronto SPV. Hence, the purpose of this study was to determine if there was early postoperative improvement in patients who received a Toronto SPV valve.

\section{METHODS}

The cardiac surgery registry at St Luke's Hospital was reviewed for all consecutive patients who underwent bioprosthetic AVR with the Toronto SPV valve $(n=100)$ or with a mechanical or stented bioprosthetic valve (CarpentierEdwards porcine SAV, Carpentier-Edwards pericardial valve, or St Jude mechanical valve) with or without other concurrent cardiac procedures in 1998-99.

The cardiac surgery registry includes preoperative data, operative data, cardiopulmonary bypass and support, postoperative information, and readmission data. These data and definitions were identified and collected according to the Society of Thoracic Surgeons/American Association for Thoracic Surgery guidelines for reporting events after cardiac valvar operations.

\section{RESULTS}

A greater proportion of the Toronto SPV group (68\%,68/100) underwent combined coronary bypass (CABG)/AVR procedures compared with the mechanical or stented bioprosthetic group $(52 \%, 39 / 75 ; p=0.03)$. Patients receiving the Toronto SPV valve were older (74.5 (6.1) v 64.9 (13.7) years; $\mathrm{p}=0.001)$, included a higher proportion of females $(52.0 \% \mathrm{v}$ $38.7 \% ; \mathrm{p}=0.080)$, and were more likely to be hypertensive $(82.0 \% \vee 70.7 \% ; p=0.077)$. No other differences in risk factors were observed between the two groups.

Preoperative cardiac status such as previous myocardial infarction, heart failure, arrhythmia, and New York Heart Association (NYHA) classification were also similar between the two groups. Likewise, there were no significant differences with regard to preoperative medications.

The mean intraoperative cross-clamp time was longer in the Toronto SPV valve patients (118 (36) v 101 (39) mins; $\mathrm{p}=0.002$ ). The difference in cross-clamp time was only marginally significant when the two groups were compared for AVR without coronary revascularisation (102 (37) $v 84$ (38) mins, $\mathrm{p}=0.052$ ). The difference in cross-clamp time between the two groups for combined CABG/AVR was even less pronounced $(126(33) \vee 116(32)$ mins; $\mathrm{p}=0.15)$.

The two groups were stratified by comparing valve size to body surface area (BSA). Patients receiving the Toronto SPV valve were smaller for any given valve size. Accrual and analysis of postoperative data revealed no significant differences in complications, mortality, and 30 day readmission rate, with the exception of the need for intra-aortic balloon counterpulsation postoperatively. Patients who received Toronto SPV valves were less likely to require intra-aortic balloon pump (IABP) support postoperatively than those who received mechanical or stented bioprosthetic valves $(0 \% \vee 2.7 \% ; p=0.020)$. Although the duration of in-hospital stay for Toronto SPV patients was less than for patients with stented mechanical or bioprosthetic valves, this difference was not significant $(10.3(8.1) \vee 12.3$ (13.7) days; $p=0.219$ ).

\section{DISCUSSION}

Analysis of the present data revealed that the Toronto SPV valve, despite its more complex implantation technique, can be safely used in complex procedures in a community hospital setting. It was found that the difference in cross-clamp time became less significant when coronary revascularisation was combined with AVR.

Furthermore, patients received a larger prosthesis relative to their BSA when a Toronto SPV was implanted than in the case of a mechanical or stented bioprosthetic valve. It is recognised that manufacturer's sizing is not standardised, and therefore a direct comparison is limited. Sizing for the Toronto SPV valve takes into account the diameter of the sinotubular junction-a measurement that is not considered for the stented valves. It is possible that the larger prosthesis size of the Toronto SPV valve is related to this method of sizing. Irrespective of the reason, in the present study the ability to implant a larger prosthesis was found to be invaluable, especially in the elderly (notable female) patients. This benefit was largely due to the lack of any need for aortic root enlargement-a procedure of potentially high morbidity in patients with calcified aortic roots. The calcified aortic root has

Abbreviations: AVR, aortic valve replacement; $B S A$, body surface area; $C A B G$, coronary artery bypass grafting; IABP, intra-aortic balloon pump; NYHA, New York Heart Association 
not hampered our ability to implant the Toronto SPV valve, the flexibility of which may conform better to the calcified aortoventricular junction, thereby reducing the risk of paravalvar leak.

In the present study, no patient in the Toronto SPV group required postoperative insertion of IABP and, when compared with the mechanical or stented bioprosthetic group, this finding was significant. It is believed that this outcome is the result of an improved patient to prosthesis size match, which thereby allows a decrease in residual left ventricular outflow tract obstruction ${ }^{3-5}$ and results in improved early postoperative haemodynamics.

In conclusion, although patients who received a Toronto SPV valve had more risk factors (age, female sex) and were more likely to require concomitant coronary revascularisation, there were no differences in either mortality or perioperative complications compared with patients receiving mechanical or bioprosthetic valves. Thus, the Toronto SPV valve displays improved immediate postoperative haemodynamics, as noted by the decreased need for IABP, and this finding is attributed in part to the superior match between valve size and BSA. The Toronto SPV valve, despite its more complex implantation technique, can be safely used in complex procedures in a community hospital setting.

\section{Authors' affiliations}

S A Olenchock, Jr, Department of Surgery, St Luke's Hospital and Health Network, Bethlehem, Pennsylvania, USA

J F Reed III, A Brown, Research Institute, St Luke's Hospital and Health Network

F M Garzia, Department of Cardiothoracic Surgery, St Luke's Hospital and Health Network

Correspondence to: Stephen A Olenchock, Jr, DO, St Luke's Hospital, Department of Surgery, 801 Ostrum Street, Bethlehem, PA 18015, USA; olenchock@pol.net

Accepted 20 November 2002

\section{REFERENCES}

1 Del Rizzo DF, Goldman BS, Christakis GT, et al. Hemodynamic benefits of the Toronto stentless valve. J Thorac Cardiovasc Surg 1996;112:1431-6. 2 David TE, Feindel CM, Scully HE, et al. Aortic valve replacement with stentless porcine aortic valves: a ten-year experience. J Heart Valve Dis 1998:7:250-4.

3 Bach DS, David TE, Yacoub M, et al. Hemodynamics and left ventricular mass regression following implantation of the Toronto SPV stentless porcine valve. Am J Cardiol 1998:82:1214-19.

4 Jin XY, Zhang ZM, Bibson DG, et al. Effects of valve substitute on changes in left ventricular function and hypertrophy after aortic valve replacement. Ann Thorac Surg 1996;62:683-0.

5 Christakis GT, Joyner C, Fremes SE, et al. Left ventricular mass regression early following aortic valve replacement. Ann Thorac Surg 1996:62:1084-9.

\section{IMAGES IN CARDIOLOGY}

\section{Submitral aneurysm: unusual echocardiographic features}

A 20 year old man presented with dyspnoea on exertion class III. Clinically he was diagnosed to have severe mitral regurgitation, possibly caused by rheumatic heart disease. The $x$ ray revealed cardiomegaly with left atrial enlargement, and pulmonary venous and arterial hypertension. The ECG suggested left atrial overload with left ventricular hypertrophy.

He underwent transthoracic two dimensional echocardiography with colour Doppler study which revealed multilobulated cystic spaces in the left atrial cavity, with colour flow within these. The mitral valve was thin and there was severe mitral regurgitation. To define the anatomy further, transoesophageal echocardiography was performed which demonstrated cystic structures as before (below left). A communication between the left ventricle and one of these

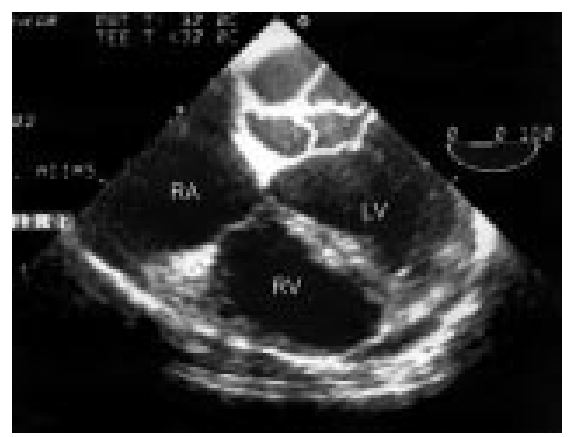

Transoesophageal echocardiogram in four chamber view showing multiple cyst-like structures in the left atrium. LV, left ventricle; $R A$, right atrium; $R V$, right ventricle. cysts was clearly seen just below the posterior mitral leaflet (below centre). A to-and-fro flow was seen on colour Doppler. With these findings the patient was diagnosed as having a submitral aneurysm of the left ventricle with severe mitral regurgitation. On cardiac catheterisation, there was moderate pulmonary arterial and pulmonary venous hypertension. Left ventricular angiogram in right anterior oblique view demonstrated filling of a multilobulated structure, close to the left atrium (below right). Severe mitral regurgitation was also confirmed.

Submitral aneurysm is a rare cardiac pathology mostly seen in African countries, particularly in the black population. It is considered to be a false aneurysm caused by a congenital defect in the posterior portion of the mitral annulus. Other aetiologies such as tuber-

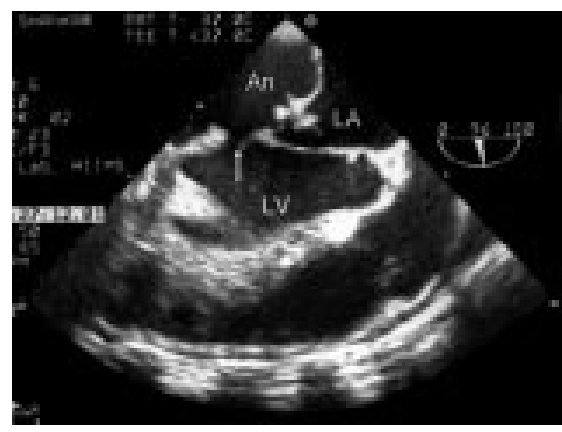

Transoesophageal echocardiogram in long axis view demonstrating the communication (arrow) of the left ventricle with the submitral aneurysm. An, aneurysm. culosis, Takayasu arteritis, and mitral valve endocarditis have been proposed. Although it can present rarely with life threatening complications such as ventricular tachycardia caused by compression of the left main coronary artery, the most common presentation is as severe mitral regurgitation.

Echocardiography usually shows it as a subpericardial echo-free space below the mural leaflet of the mitral valve, which communicates with the ventricular cavity. Our case presented with interesting echocardiographic features, not reported previously.

A Mohanty A Saxena anitasaxena@hotmail.com

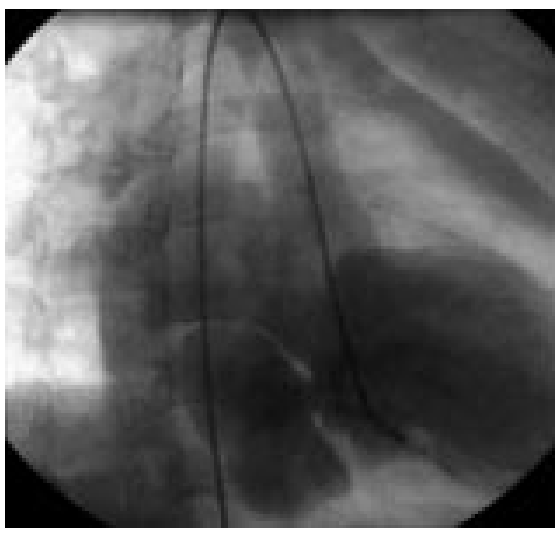

Left ventricular angiogram in right anterior oblique view showing filling of the lobulated submitral aneurysm and severe mitral regurgitation. 